\title{
CORRECTION
}

\section{Correction: Limits to the cellular control of sequestered cryptophyte prey in the marine ciliate Mesodinium rubrum}

Andreas Altenburger (D), Huimin Cai (D), Qiye Li, Kirstine Drumm, Miran Kim, Yuanzhen Zhu, Lydia Garcia-Cuetos, Xiaoyu Zhan, Per Juel Hansen (iD, Uwe John (D), Shuaicheng Li (iD) and Nina Lundholm (iD)

(C) The Author(s), under exclusive licence to International Society for Microbial Ecology 2021

The ISME Journal (2022) 16:898; https://doi.org/10.1038/s41396-021-01115-5

Correction to: ISMEJ https://doi.org/10.1038/s41396-020-00830-9

Following the publication of this article the authors noted an error in a sub-section of the methods.

This has now been corrected to read:

“DNA extraction
For DNA extraction T. amphioxeia cells as well as starved M. rubrum (fed T. amphioxeia) cells were harvested as described above and DNA extracted using a KingFisher Duo Prime System (\#5400110, Thermo Fisher Scientific, Waltham, USA) using the Plant DNA Kit and following the manufacturers recommendations."

This correction has no effect on the results or conclusions drawn.

The original article has been corrected. 